\title{
INTERCEPTIVE MANAGEMENT OF MIDLINE DIASTEMA RELATED TO MESIODENS: A CASE REPORT
}

\author{
Dr. Mamta Dali ${ }^{1}$, Dr. Parajeeta Dikshit ${ }^{2}$, Dr. Sandhya Joshi' ${ }^{3}$, Prof. Dr. Arathi Rao ${ }^{4}$ \\ 1,3 Lecturer, Dept of Pedodontics \& Preventive Dentistry, Kist Medical \& Dental College, Lalitpaur, Nepal. \\ ${ }^{2}$ Lecturer, Dept of Pedodontics \& Preventive Dentistry, Kantipur Dental College, Kathmandu, Nepal. \\ ${ }^{4} \mathrm{MCODH}$, Manglor \\ E-mail: mamatadali@hotmail.com
}

\section{ABSTRACT}

Supernumerary teeth which occur both in the primary and the permanent dentition are seen more frequently in the permanent dentition causing a variety of pathological and occlusal disturbances. Presented herewith is a case report of a patient with a mesiodens which had caused problem in esthetic appearance and spontaneous eruption of right sided upper lateral incisor. Extraction of the mesiodens was carried out, subsequently followed by the space closure utilizing simple fixed orthodontic therapy.

Key words: Interceptive orthodontics, Malocclusion, Mesiodens, Midline diastema

\section{INTRODUCTION}

Supernumerary teeth are teeth in excess of the normal number which can occur in both primary and permanent dentitions. A mesiodens is the most common supernumerary (extra) tooth. It is located in the maxilla in the midline (hence the special name which means "middle tooth"). The etiology is unknown, but hyperactivity of the dental lamina is the most widely accepted theory. In some cases, there appears to be a hereditary tendency for the development of supernumerary teeth. ${ }^{1}$ The prevalence has been estimated to be 0.15 to $2.2 \%$ of the population with a preference to male. ${ }^{2}$ Mesiodens is usually found to be impacted but can also be fully or ectopically erupted. ${ }^{2,3}$ The presence of a mesiodens or supernumerary teeth in the maxillary arch could be deleterious from the esthetic and functional point of view. Although the literature associates these problems as etiological factors to midline diastema, the presence of both situations in the same patient is very uncommon. ${ }^{4}$ The Pediatric Dentistry practice include incorporation of more interceptive orthodontic procedures. If children receive proper guidance in the development of occlusion and appropriate orthodontic treatment, they will reach adulthood with aesthetic and functional occlusion. Certain phases of orthodontic treatment are very well within the realm of pediatric dentistry as pediatric dentists come across children at the earliest. Early recognition and interception could avoid long term laborious orthodontic treatment. Interceptive procedures are required for developing basal dysplasia, cleft palate problems, anterior diastema, habit problems, arch length deficiency problems and so forth. ${ }^{5}$

It is strongly advised that the diagnosis of mesiodens should be made as early as possible due to its association with disturbances in tooth eruption such as delayed eruption of the permanent incisors, crowding or interference with the alignment of the maxillary incisors, dental impaction, resorption of adjacent tooth, development of dentigerous cyst and one of the most common sequel, a midline diastema..$^{1,3}$

Since there is a lack of information in the literature regarding patients with midline diastema associated to mesiodens, it is necessary to report clinical cases in order to facilitate the knowledge of this issue. 6,8

The purpose of this article is to present a case report of a 9 year-old boy with mesiodens causing midline diastema which was treated with a simple interceptive orthodontic approach achieving satisfactory results.

\section{CASE REPORT}

A 9 year-old boy reported to the Department of Pediatric Dentistry, Manipal College of Dental Sciences, Mangalore 
with the complaint of extra tooth in the upper jaw causing esthetic problem. His medical and dental histories were uneventful. Intraoral examination revealed that the patient was in the mixed dentition, with mesiodens on upper anterior region; and with the permanent maxillary incisors and first molars already erupted.

In addition there was labially erupting 12 and 21 (Fig.1). The IOPA radiograph of the region ruled out the presence of any other unerupted supernumerary tooth (Fig.2). The treatment plan was designed to accomplish some clinical objectives such as the removal of the mesiodens and the orthodontic closure of the midline diastema which would cause guided eruption of 12 and correct labially erupting 21 to normal arch alignment.

After the consent was obtained from the parents, the mesiodens was extracted under local anaesthesia (Fig.3) and patient was reviewed after 2 weeks for further treatment. The healing of extraction socket was satisfactory (Fig.4). A thorough oral prophylaxis was done and then preceded for space closure using simple fixed appliance therapy. Next, sectional orthodontic Begg brackets were bonded on the labial surface of the maxillary central incisors and orthodontic elastic was placed in a figure of ' 8 ' pattern to close the diastema (Fig.5 a,b).

The patient was recalled for routine check up after 1 week and it was observed that patient had adapted well to the appliance. At this stage, the patient was provided with the elastics and was asked to change elastics every day and instructions regarding oral hygiene maintenance were given. The patient was followed up every month for a period of 2 months. After two months, diastema was closed creating enough space for spontaneous eruption of the 12 (Fig.6). At this stage, as the orthodontic brackets were removed (Fig.7) and a palatal bonded retention was placed in the maxillary central incisors to avoid relapse (Fig.8). The analysis of the final photographs shows the reestablishment of normal dental development highlighting the efficiency and effectiveness of the treatment. Furthermore, due to the esthetic improvement, the patient reported a higher level of self-confidence and was happier (Fig.9).

\section{DISCUSSION}

Supernumerary permanent teeth are most common in the anterior region of the maxilla and occasionally reported in mandibular central incisors and molar areas 9,10 . The presence of a supernumerary tooth in the primary dentition should not be ignored. It should however alert the clinician for a thorough examination since there is an increased chance of supernumerary teeth in the permanent dentition also. ${ }^{11,12}$ The optimal time for surgical removal of a supernumerary tooth is controversial; immediate versus delayed removal. Immediate intervention calls for removal of the supernumerary tooth soon after diagnosis. On the other hand, delayed intervention indicates removal should not be done until adjacent root formation is complete. The early diagnosis of large midline diastema and erupted mesiodens is more common because they are located in the maxillary anterior region and are easily noticed by parents or general practitioners or pediatric dentists. ${ }^{13}$ The literature supports the cause and effect relation between the mesiodens and the midline diastema. ${ }^{14}$

Supernumerary teeth, such as mesiodens are said to deflect the eruption pattern of the maxillary central incisors or physically move the incisors laterally to create midline spacing. ${ }^{5}$ In the case reported, the eruption of both central incisors was satisfactory but the erupted mesiodens had interfered the spontaneous eruption of 12. Other multiple factors which may contribute to a midline space are oral habits, soft issue imbalances, physical impediment, dental anomalies and/or skeletal disharmonies as well as normal dento-alveolar development. ${ }^{5}$

Removal of mesiodens followed by orthodontic diastema closure can be divided into four groups:

(i) Treatment involving mesial tipping movement of incisors ${ }^{15,16}$

(ii) Treatment involving mesial bodily approximation of the incisors ${ }^{17}$

(iii) Treatment involving the decrease of an enlarged overjet properly

(iv) Closing the space as part of more comprehensive orthodontic treatment

In the present case, diastema closure was performed using a treatment procedure which involved mesial bodily approximation of the incisors with simple fixed orthodontic therapy. Since most maxillary midline diastema recur even after the best managed treatment, permanent retention is required in most cases. Lingual bonded fixed retainer, straight sectional wires, ligature wires etc have been recommended for the retention therapy. ${ }^{18}$ In this case, after space closure, ligature wires were used for the retention, after which the permanent lateral incisors would not allow the distal movement of the maxillary central incisors thereby preventing any relapse. 
Early developing malocclusion should be intercepted with the goal of restoring a normal occlusion. The time and degree of interception are the major problems of interceptive stage, which if dealt properly, can produce positive results in the mixed dentition as seen in the present case of interceptive orthodontic management of midline diastema related to mesiodens.

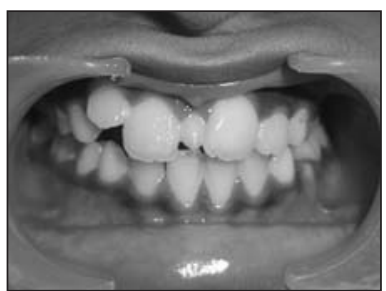

Fig. 1 Closure of diastema

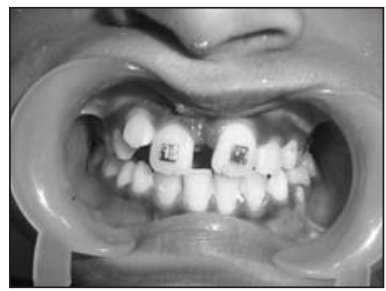

Fig.4 Extracted mesiodens

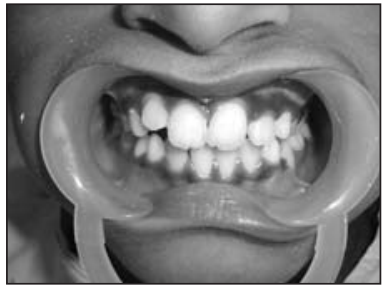

Fig.7 After 2 month, closure of midline diastema.

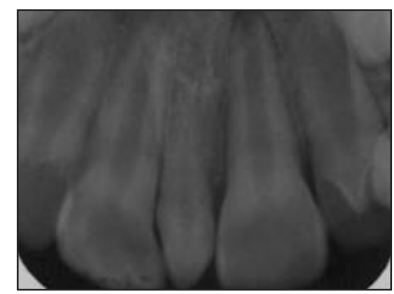

Fig. 2 Presence of mesiodens between 11 and 21 .

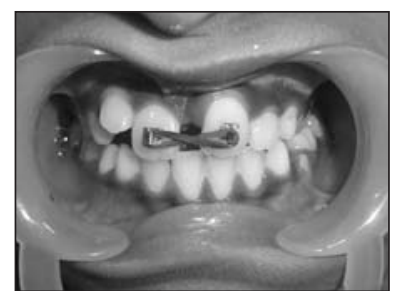

Fig.5 Orthodontic bracket bonded on 11,21

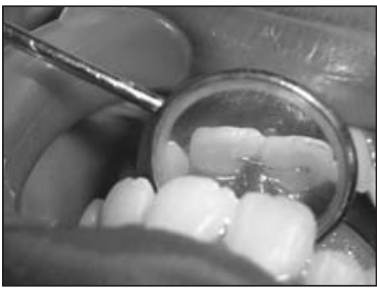

Fig.8 Palatal retainer placed to 11 and 21

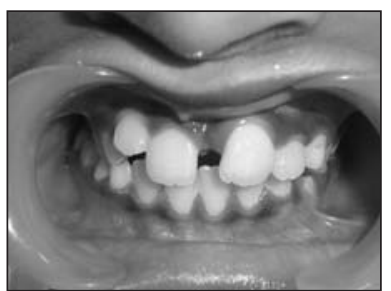

Fig. 3 Healing of socket

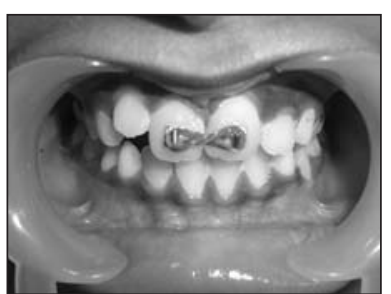

Fig. 6 Orthodontic elastic in figure of 8

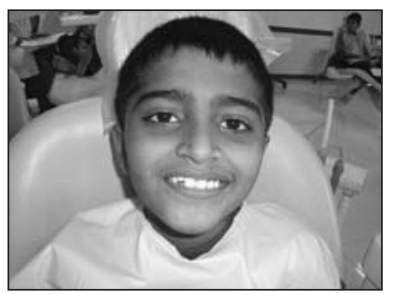

Fig.9 Final photograph of the patient's smile

\section{REFERENCES}

1 Nallanchakrava S. Complexity at its simplest by interceptive orthodontics. Int Journal of Contemporary Dentistry 2011;93-96. Gundu K, Celenk P, Zengin Z, Sumer P. Mesiodens. A radiographic study in children. J Oral Sci 2008;50:287-91.

Roychoudhury A, Gupta Y, Parkash H. Mesiodens. A retrospective study of fifty teeth. J Indian Soc Pedo Prev Dent 2000;18: 144-6.

Yamaoka M, Furusa K, Yasuda W. Effects of maxillary anterior supernumerary impacted teeth on diastema. Oral Surg Oral Med Oral Pathol Oral Radiol Endod. 1995;80: 252.

5 Munshi A, Munshi A K. Midline space closure in the mixed dentition: A case report. J Indian Soc Pedo Prev Dent 2001:19:2:57-60.

6 Almeida RR, Garib DG, Almeida-Pedrin RR, Almeida MR, Pinzan A, Junqueira MHZ. Diastema interincisivos centrais superiores: quando e como intervir ? Rev Dental Press Ortodon Ortoped Facial 2004;9:137-56.

7 Tostes MA, Fernandes KP. Dente supranumerario diastema mediano. Superior/ Supernumerary tooth and superior median diastema. RGO 1996;44:220-3.

8 Heluy DB, Portella W, Gleiser R. Supranumerario (mesiodent) sua influencia no diastema mediano superior: relato de um caso na F.O.UFRJ. Rev odontopediatr 1993;2:165-70.

9 Sharer WG, Hine MK, Levy BM. A textbook of oral pathology. 4th ed. Philadelphia: WB Saunders Co, 1983:47-50.

10 Luten JR. The prevalence of supernumerary teeth in primary and mixed dentitions. ASDC J Dent Child 1967; 34(5):346-53.

11 Jarvinen S, Lehtinen L. Supernumerary and congenially missing primary teeth in Finnish children. Acta Odontol Scand 1981; 39:83-6.

12 Trenouth MJ, Bedi R. Supernumerary primary first molar and first premolar. Clinical report. Pediatr Dent 1983;5(3):214-16.

13 Uematsu S, Uematsu T, Furusawa K, Degushi T, Kurihara S. Orthodontic treatment of an impacted dilacerated maxillary central incisor combined with surgical exposure and apicocectomy. Angle Orthod 2004;74:132-6.

14 Machado A, Ambrosio A, Godeiro F, Rabelo Caldas, Gonzaga L. Orthodontic treatment of a midline diastema related to mesiodens and thumbsucking habit. Rev. odonto cienc. 2010;25(3):314-318.

15 Offerman R E. A diastema closing device. J Clm Orthod 1984,18 430-31.

16 Mlyajlma K, Shlrakama K, Senda A. Application of porcelain veneers following orthodontic treatment. J Can Dent Assoc 1993, 59 167-70.

17 Banker C A, Berpocher W G, Mueller B H. Alternative methods for the management of persistent maxillary central diastema. Gen Dent 1982. 30 136-39.

18 Edwards J G. A clinical study the diastema the frenum, the frenectomy Oral Health 1977, 67 (9) 51-62. 